\title{
ESTIMATION OF THE OUTCOME OF A STANDING MENTAL HOSPITAL POPULATION •
}

\author{
BY \\ J. A. BALDWIN AND D. J. HALL \\ Department of Mental Health, University of Aberdeen
}

A review of surveys of mental hospital populations in Britain in the 1960s carried out for planning purposes reveals conflicting conclusions about the likely requirement for mental hospital beds over the next 15 to 20 years - the period over which estimates are needed for planning facilities. The estimate on which the Hospital Plan for England and Wales (National Health Service, 1962) was based assumed a fall from over three beds per thousand total population in 1961 to about 1.8 per thousand by 1975 (Tooth and Brooke, 1961). Cross and Yates (1961) reported broadly similar estimates based on the Birmingham region. Criticisms of the estimates in the Hospital Plan emphasized the regional variation in current bed provision and the self-fulfilling character of prophecies of this kind when they are acted upon (Baldwin, 1963; Rehin and Martin, 1963), and the low expectation of separation from hospital by death or discharge of the high proportion of relatively young long-stay patients (Gore and Jones, 1961). Earlier optimism about the possibilities of rehabilitation of long-stay patients and reduction of requirements for long-term beds (Cooper and Early, 1961; Norton, 1961) has been tempered by more recent studies which have expressed doubt as to the likelihood of fulfilment of the original estimates (Hassall and Hellon, 1964; Early and Magnus, 1966). It has also been shown that large differences exist in the behaviour of individual hospitals and of age and sex groups within hospitals, so that a uniform measure of bed needs could be misleading (Hassall, Spencer, and Cross, 1965).

The problem of projecting the future size and structure of a mental hospital population on the basis of past and current use is usually subdivided into consideration of two interrelated processes:

(1) The expected trend in the number of future admissions and their duration of stay or bed usage.
(2) The expected attrition of the standing mental hospital population existing at the beginning of the projection period by death or discharge.

This paper deals exclusively with the second of these processes.

Tooth and Brooke (1961) based their calculation on the annual rate of separation (i.e. discharge and $\frac{7}{0}$ death) of the standing long-stay hospital population (over 2 years) at the end of 1954, assuming a linear $\vec{\bullet}$ fall to extinction in 16 years. It was subsequent $\$$ o pointed out that the assumption of linear attritio was almost certainly incorrect even on the basis the original data (Lindsay, 1962). Lindsay showe that application of the annual separation rates to the patients in the original standing long-stay population remaining in hospital at the end of each year would represent a decreasing geometric series and not an arithmetic series, so that projection would result in a curve yielding a quarter of the patients remaining after 20 years, i.e. by 1974. Norton (1961) had also projected in a curvilinear fashion from data on actual separation experience over 6 years.

In order to improve the accuracy and usefulness of projections of this kind, a detailed study was undertaken to develop a method of forecasting which would make use of direct estimates of the probability of separation occuring after specified $\stackrel{9}{\triangle}$ lengths of stay in hospital for any defined group $\frac{D}{O}$ of patients, such as an age, sex, or diagnostic group. A further objective of the study was to allow $N$ for the effect of ageing of the population remaining in hospital, so that the age composition of the residue o could also be anticipated for any projection period. $\omega$

\section{METHOD}

Perhaps the most obvious approach to this prob- $\stackrel{?}{?}$ lem would be to apply standard life-table method to the cohorts of admissions, the residues of which 
compose a resident mental hospital population. A common practical difficulty is that sufficient data are not normally available, so that an application of this type would require special arrangements which could not be made repeatedly. It would be more satisfactory if an adaptation could be devised which permitted use of commonly available recent information such as admission or separation data.

The method proposed utilizes data on all separations from hospital in the chosen year. Patients in the whole standing hospital population at the point of time under consideration are referred to as residents. The various time periods relating to patients entering and leaving the resident population are defined as follows: duration of stay is the total time elapsing between admission and separation; hospital age is the period of time spent in hospital of resident patients; continued stay is the period of stay remaining to resident patients up to their separation. A period of $n$ years means more than $n$ years but less than $n+1$ years.

Consider first the whole group of separations subdivided according to their duration of stay in years. These can be shown graphically as a column built up of blocks, each representing patients separated after a duration of stay of a specified number of years and proportional in size to the number of patients in the group. The blocks are arranged in order of duration of stay with the longest at the bottom (Fig. 1).

\begin{tabular}{|l|}
\hline 0 \\
\hline 1 \\
\hline 2 \\
\hline 3 \\
\hline 4 \\
\hline 5 \\
\hline
\end{tabular}

Fig. 1.-Block diagram of hypothetical separations, by duration of stay in years.

Next consider the hospital age composition of this same population one year previously. For instance, how were (hypothetical) 1964 separations distributed by hospital age in 1963 ? The column will differ in two respects:

(1) The top block of the column will have disappeared, since patients with less than one year in hospital in 1964 were not there in 1963.

(2) The remaining numbered blocks in the column will be equal in size but will represent periods of stay precisely one year shorter.
This process can be continued to its conclusion when none of the patients separating in the year under consideration would have been in hospital (Fig. 2).

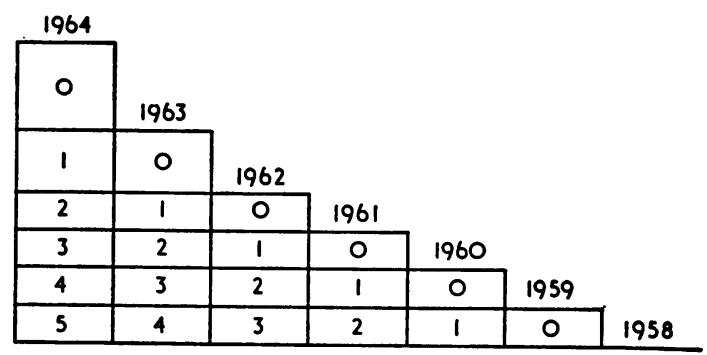

FIG. 2.-Block diagram of hypothetical separations in 1964 by duration of stay in years traced back to year of admission.

The question which the method must answer is "for any given patient, what is the probability of his continued stay in hospital for any specified period?" Such a table of probabilities can be obtained from the distribution of separations in the reference year by duration of stay as follows: begin by considering all patients separated in 1964 who, at some stage, had had a hospital age of 1 year-that is, all patients in blocks labelled 1 in Fig. 2. Of these, some will have a continued stay of 4 years, some 3 , some 2 , some 1 , and some 0 years, the proportion in each of these categories being equal to the size of the corresponding block divided by the total size of all blocks containing 1.

However, all blocks along a "horizontal" in Fig. 2 are of equal size because they represent the same patients. Thus only the blocks in the tallest or most recent column (1964 in Fig. 2) need be considered. Therefore the proportion of patients who were, at some time, of hospital age 1 year, and who remained in hospital for a further 3 but less than 4 years, is obtained from the blocks in the column for 1964 as follows:

$$
\frac{\text { block } 4}{\text { block } 1+\text { block } 2+\text { block } 3+\text { block } 4+\text { block } 5}
$$

Similarly, proportions can be calculated for all the actual continued stays and all the actual hospital ages.

These proportions are, in effect, probabilities or relative frequencies of separation and could be used without further adjustment if the number of admissions in each year of the whole period under consideration had been constant. If the same numbers had not been admitted in each year, the results would be affected by the number of admissions as well as by 
their duration of stay, so that it is necessary to adjust the separation figures to the values they would have had if the number of admissions had been constant by dividing the separations in each duration of stay block by the number of admissions in the year in which they were admitted. This has the effect of keeping the risk population constant. The probabilities can then be computed using these "adjusted separations". If, as in most areas, the number of admissions had been rising for some years, the effect of using unadjusted separation figures would be to set the probability of early separation too high and that of later separation too low. The effect of the correction is shown in the results section of this paper. Table $I$ is a sample working Table. In practice it seemed advisable to aggregate separations for three consecutive years in order to reduce random fluctuations in the results.

If the whole set of probabilities so calculated is applied to the resident hospital population from which the separations were drawn, a projection is obtained of the number of separations per year from it, to the point of extinction. The projection is a statement of the number of patients who will leave and the number who will remain in hospital after each year, if the probability of separation remains the same in all subsequent years.

It should be noted that application of the probability matrix to a resident population on one day of the year introduces an error of size and sign equivalent to the difference between mean and one-day resident figures. In practice this may not be large, but does tend to be greatest for the hospital age categories in which separation rates are highest, that is, for periods less than one year. In this study, both bases were used, and a set of comparative results is presented.
The mathematics of the method are detailed in the Appendix. The extensive calculations for this study were carried out by computer and the necessary programmes are available in Algol from the authors.

\section{Results}

The method was applied to data relating to residents in and separations from North-East Scottish mental hospitals over the period 1955 to 1964 , and a selection of results is presented to illustrate the main features and their implications.

\section{Projected Outcome of the Mental Hospital POPUlation of 1963}

The earliest year for which sufficiently detailed data could be obtained to carry out a reasonably accurate computation was 1963 , the first year of operation of the psychiatric case register (Baldwin, Innes, Millar, Sharp, and Dorricott, 1965). Accurate information on admissions for the period 1956 to 1961 was kindly made available from the Scottish Home and Health Department. For the years before 1956, admissions were estimated by extrapolation from the figures for Scotland as a whole, these data enabling adjustment of separations by sex, but not by age. Case register data relating to residents in mental hospitals permitted calculation of the mean resident population for 1963 , but not for earlier years. No admission or separation data were available for the year 1962. As the number of years for which full information is available increases, the accuracy of projection should improve.

The most striking general result was that the decline of a given mental hospital population would be expected to follow a more or less curved rather

PROBABILITY TABLE FOR CONTINUED STAY,

Based on 1957, "

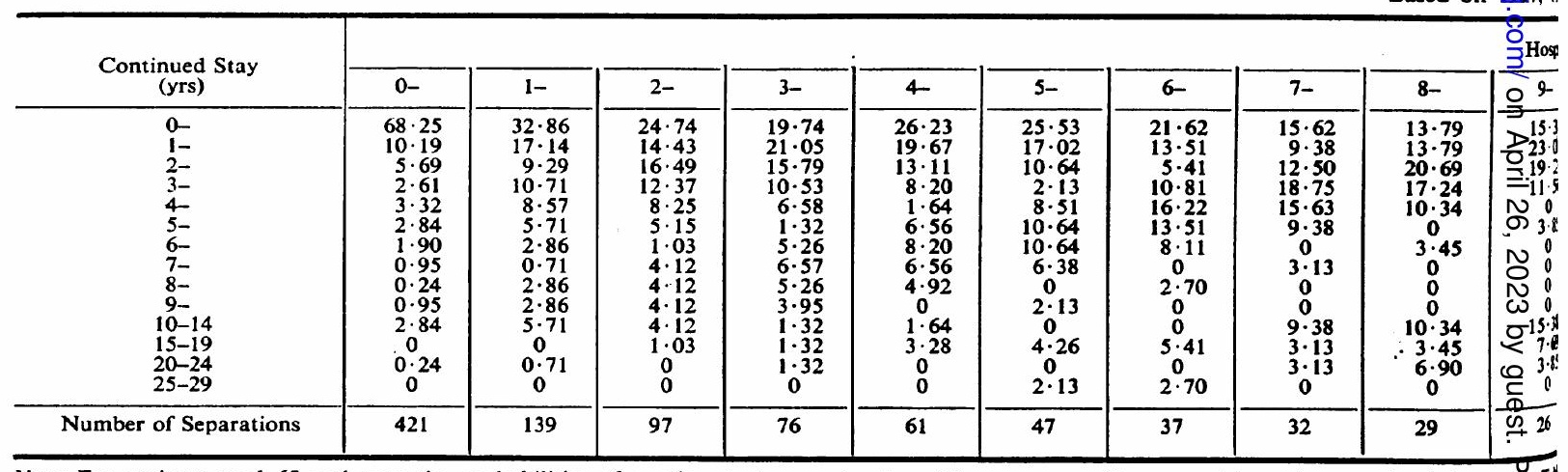




than a straight line (Fig. 3). The main implication is that, although the time which would elapse for the population to be halved may be quite short ( 7 years for the mean resident population separating according to the adjusted probability of separation for 1960 , 1961, and 1963), the time required for complete elimination would be over 50 years. Indeed, considering long-stay patients (hospital age over 2 years) only, these results accord closely with Lindsay's calculation of a quarter remaining after 20 years. In this example a quarter would remain after 22 years.

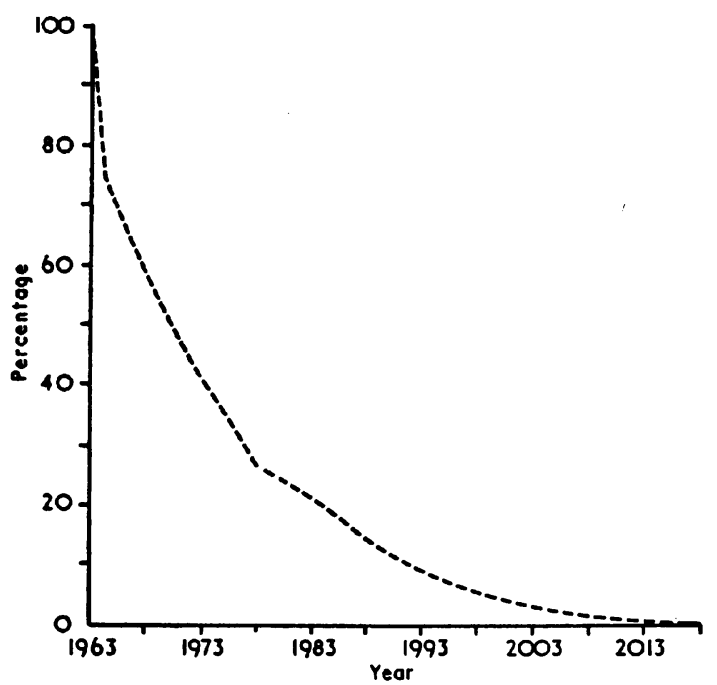

Fig. 3.-Projected outcome of mean resident population in 1963. based on adjusted probability of separation in 1960, 1961, and 1963,

Separate results for all resident males and females reveal differences of considerable importance (Fig. 4). Whereas the half life (time elapsing for 50 per cent. of the population remaining) for females was 5-6 years, that for males was 9-10 years. The quarter life (time elapsing for 25 per cent. remaining) was $15 \frac{1}{2}$ years for females and $20 \frac{1}{2}$ years for males.

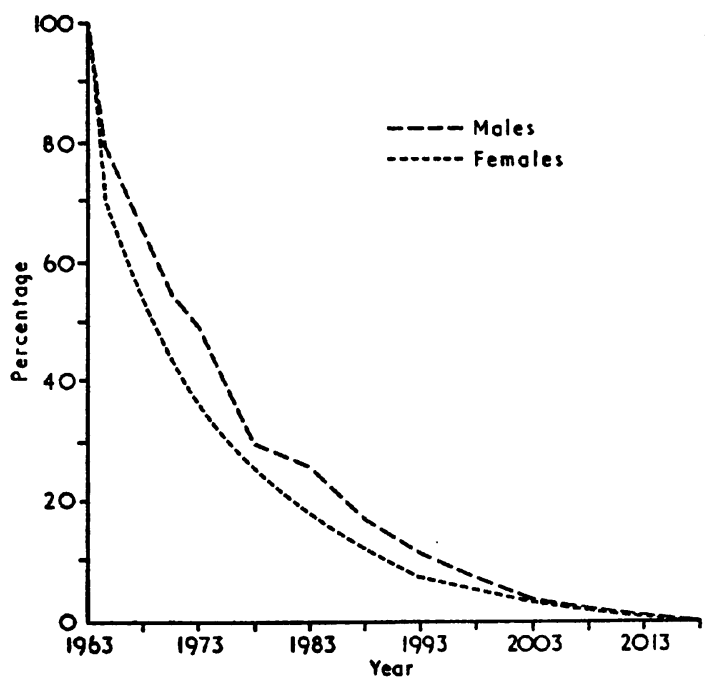

FIG. 4.-Projected outcome of mean resident population in 1963 by sex, based on adjusted probability of separation in 1960, 1961, and 1963.

As might be expected, marked differences were found for different age groups (Fig. 5, overleaf). The half life for young patients was about 18 months, for the middle-aged 12 years, and for old patients 4 years. In contrast, the quarter life of young patients was 28 years, for the middle-aged 24 years, and for old patients 8-9 years.

Sex differences also appeared within the young and middle-aged. The female population would be reduced more rapidly than the male in both, the most

\begin{tabular}{|c|c|c|c|c|c|c|c|c|c|c|c|}
\hline $11-$ & $12-$ & $13-$ & 14- & $15-19$ & $20-24$ & $25-29$ & $30-34$ & $35-39$ & $40-44$ & $45-49$ & $50-54$ \\
\hline $\begin{array}{c}23 \cdot 81 \\
14 \cdot 29 \\
4.76 \\
9.52 \\
0 \\
0 \\
4 \cdot 76 \\
0 \\
4 \cdot 76 \\
4 \cdot 76 \\
19.05 \\
9.52 \\
4.76 \\
0\end{array}$ & $\begin{array}{c}16 \cdot 67 \\
5 \cdot 56 \\
11 \cdot 11 \\
0 \\
0 \\
11 \cdot 11 \\
0 \\
5 \cdot 56 \\
5 \cdot 56 \\
11 \cdot 11 \\
16 \cdot 67 \\
16 \cdot 67 \\
0 \\
0\end{array}$ & $\begin{array}{c}5 \cdot 26 \\
10 \cdot 53 \\
5 \cdot 26 \\
0 \\
10 \cdot 53 \\
0 \\
10 \cdot 53 \\
5 \cdot 26 \\
10.53 \\
0 \\
21 \cdot 05 \\
21.05 \\
0 \\
0\end{array}$ & $\begin{array}{c}10 \cdot 53 \\
5 \cdot 26 \\
0 \\
10 \cdot 53 \\
0 \\
10 \cdot 53 \\
10 \cdot 53 \\
10 \cdot 53 \\
0 \\
10 \cdot 53 \\
21 \cdot 05 \\
10 \cdot 53 \\
0 \\
0\end{array}$ & $\begin{array}{c}5.88 \\
7.06 \\
9.41 \\
7.06 \\
9.41 \\
7.00 \\
5.88 \\
3.53 \\
.4 .71 \\
4.71 \\
22.35 \\
9.41 \\
3.53 \\
0\end{array}$ & $\begin{array}{r}10 \cdot 17 \\
10 \cdot 17 \\
6 \cdot 78 \\
8 \cdot 47 \\
6 \cdot 78 \\
6 \cdot 78 \\
5 \cdot 08 \\
6 \cdot 78 \\
8 \cdot 47 \\
5 \cdot 08 \\
13 \cdot 56 \\
8 \cdot 47 \\
0 \\
3 \cdot 39\end{array}$ & $\begin{array}{r}9.80 \\
5.88 \\
7.84 \\
11.76 \\
7.84 \\
7.84 \\
9.80 \\
5.88 \\
1.96 \\
0 \\
9.80 \\
0 \\
11.76 \\
9.80\end{array}$ & $\begin{array}{c}7.69 \\
9.62 \\
9.62 \\
5.77 \\
5.77 \\
7.69 \\
3.85 \\
3.85 \\
1.92 \\
1.92 \\
11.54 \\
13.46 \\
17.30 \\
0\end{array}$ & $\begin{array}{c}9 \cdot 09 \\
6 \cdot 82 \\
4 \cdot 55 \\
2 \cdot 27 \\
2 \cdot 27 \\
0 \\
2 \cdot 27 \\
4 \cdot 55 \\
4 \cdot 55 \\
6 \cdot 82 \\
22 \cdot 73 \\
34 \cdot 09 \\
0 \\
0\end{array}$ & $\begin{array}{c}0 \\
2 \cdot 13 \\
4 \cdot 26 \\
4 \cdot 26 \\
8 \cdot 51 \\
8 \cdot 51 \\
8 \cdot 51 \\
6 \cdot 38 \\
8 \cdot 51 \\
6 \cdot 38 \\
38 \cdot 30 \\
4 \cdot 26 \\
0 \\
0\end{array}$ & $\begin{array}{c}9 \cdot 76 \\
9 \cdot 76 \\
9 \cdot 76 \\
12 \cdot 20 \\
7 \cdot 32 \\
9 \cdot 76 \\
12 \cdot 20 \\
9 \cdot 76 \\
7 \cdot 32 \\
7 \cdot 32 \\
4 \cdot 88 \\
0 \\
0 \\
0\end{array}$ & $\begin{array}{c}19 \cdot 05 \\
23 \cdot 81 \\
19 \cdot 05 \\
14 \cdot 29 \\
14 \cdot 29 \\
9 \cdot 52 \\
0 \\
0 \\
0 \\
0 \\
0 \\
0 \\
0 \\
0\end{array}$ \\
\hline 21 & 18 & 19 & 19 & 86 & 58 & 51 & 52 & 44 & 49 & 41 & 21 \\
\hline
\end{tabular}




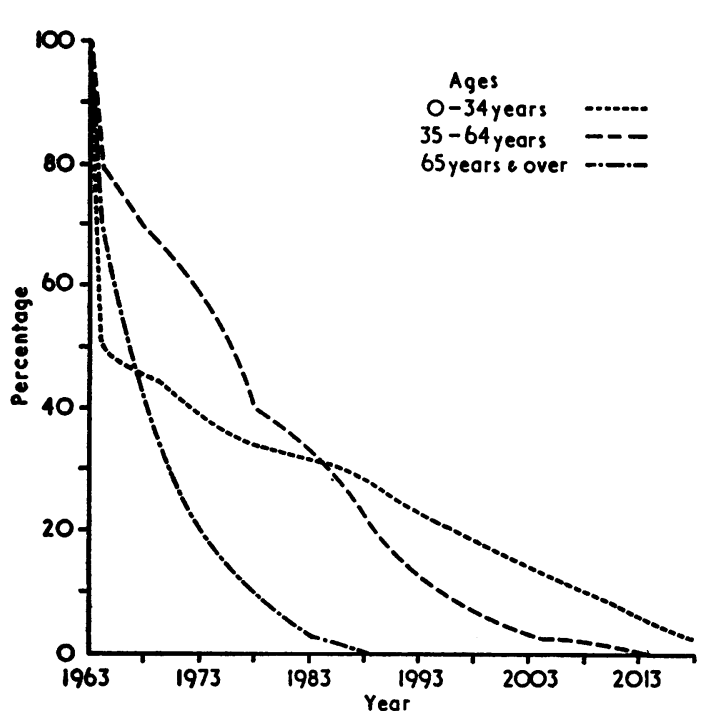

Fig. 5.-Projected outcome of mean resident population in 1963 by age, based on adjusted probability of separation in 1960,1961. and 1964.

marked difference being among patients aged 0-34 years (Figs 6 and 7).

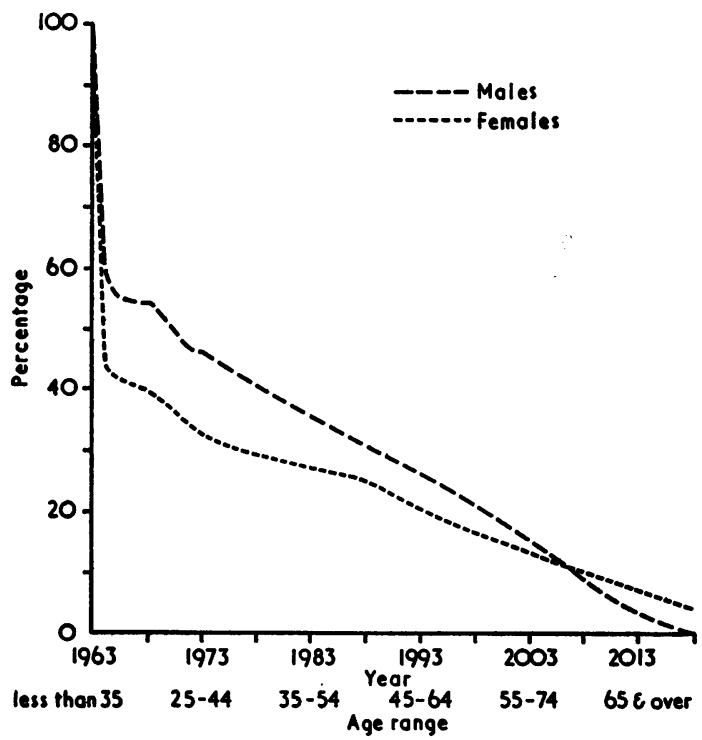

Fio. 6.-Projected outcome of mean resident population in 1963 aged 0-34 years, based on adjusted probability of separation in 1960,1961 , and 1963.

The sex differences in outcome of aged patients were negligible (Fig. 8).

\section{Changes in Projected Outcome Over Time}

One aspect on which it would be important to

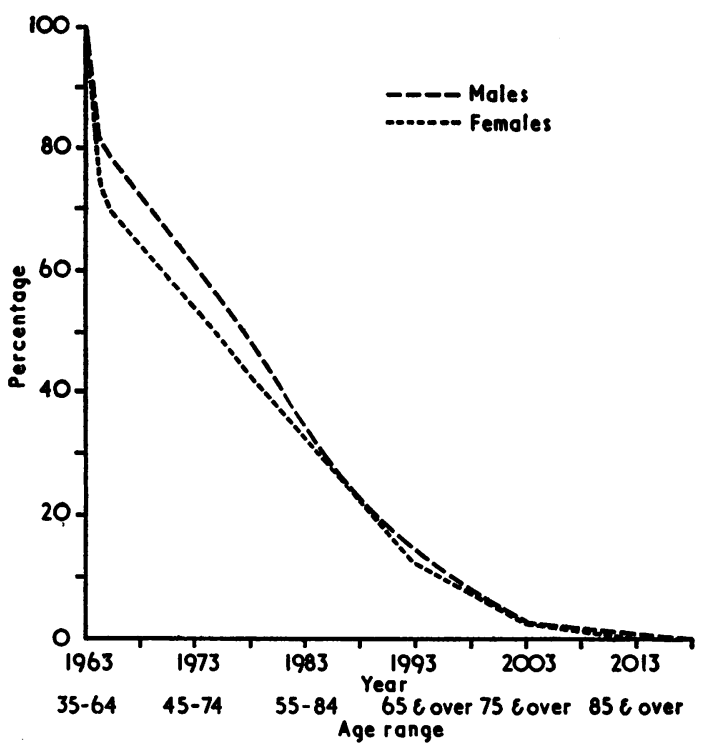

Fig. 7.-Projected outcome of mean resident population in 1963 aged 35-64 years by sex, based on adjusted probability of separation in 1960,1961 , and 1963.

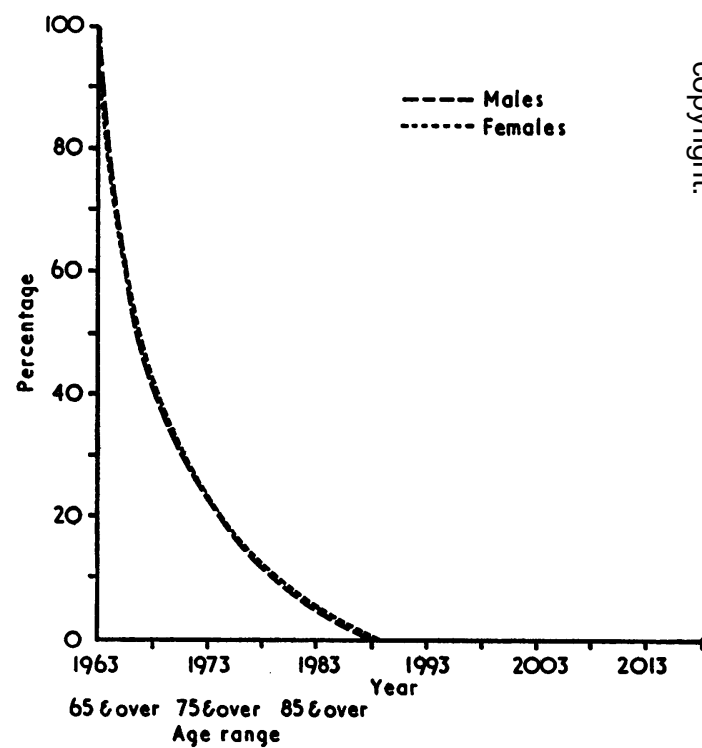

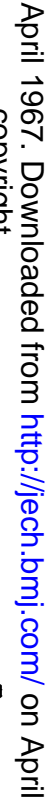

Fig. 8.-Projected outcome of mean resident population in $1963 \mathrm{~N}$ aged 65 years and over by sex, based on adjusted probability of $\sigma$ separation in 1960, 1961, and 1963.

obtain information for planning purposes is the extent to which there has been a change in the probable outcome with time. Clearly, if the expect- $\varrho$ ation of separation of a standing mental hospital population were to change, the rate at which it: would decline would also change. One way of investi- $\frac{T}{3}$ gating this problem is to apply the probabilities of $\frac{D}{\mathbb{D}}$ 


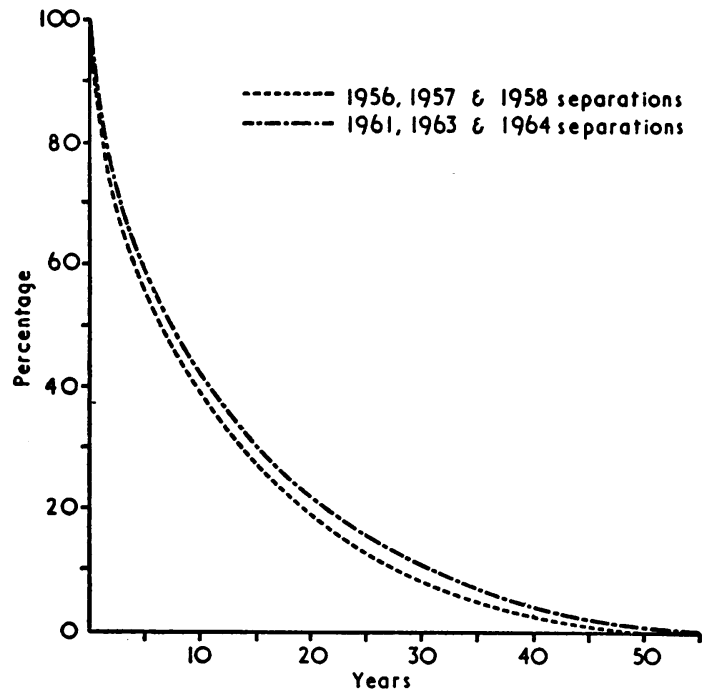

FIG. 9.-Projected outcome of resident population on December 31, 1955 , based on unadjusted probability of separation in 1956, 1957, and 1958, compared with unadjusted probability of separation in 1961,1963 , and 1964 .

separation obtained from different years to a fixed resident population. In Fig. 9, two such sets of probabilities are applied to the population of the mental hospitals at the end of 1955 (it will be shown that the difference between mean and end of year populations is not important). It can be seen that there is very little difference over the period, but there was a slight tendency for the proportion remaining after specified intervals to increase with time. The separation data were not adjusted for changes in number of admissions in this example, but validity of comparison of the two projection curves is not greatly impaired, although adjustment of the separations would accentuate the difference. Thus, if the 1955 population were to separate according to the probabilities for 1961, 1963, and 1964, it would take slightly longer than if it were to separate according to the probabilities for 1956, 1957, and 1958. Similar computations for intervening years tend to confirm these results.
Projected Age and Sex Composition of the Mental Hospital Population of 1964

For planning purposes it is not sufficient to know only the numbers of a standing hospital population who will remain after any period. It is necessary to know also at least the future sex and age composition, and it would be helpful to know something about the diagnostic distribution and perhaps other features as well. In principle, the method permits any of these characteristics to be taken into account in computing the projection, providing only that the requisite data are available. This study was limited to projection of the sex and age composition for 1964, the latest year for which data were available.

Since the patients remaining after each interval of the projection increase in age by the length of the interval, the age range of those remaining can be stated for any elapsed time. Provided numbers are sufficiently large, age groups can be made small enough to increase the detail with which the age structure can be described. The data presented in Figs 3 to 9 were based on the three large age groups, 0-34 years, 35-64 years, and 65 years and over, and only the broadest indication of future age structure can be derived. By computing separate probabilities for each 10-year age group, the projected age structure can be specified at 10-year intervals. The results of this type of projection for 1964 residents in mental hospitals are shown in Table II with the 10-year age groups amalgamated into three broad categories. The first row of the Table shows the age and sex composition of the mental hospital population at the end of 1964. The second and subsequent rows show the expected age and sex composition of those remaining after each 10-year interval. It should be noted that, since adjustment of separation data for changes in the number of admissions was not possible by age, these results will not be as reliable as could have been obtained with more complete data.

The results show that the numerical predominance of the male long-term population over the female, which is a long-standing feature of North-East Scottish mental hospitals in common with most

TABLE II

MEAN RESIDENT POPULATION OF NORTH-EAST SCOTTISH MENTAL HOSPITALS IN 1964 Projected composition at 10-year intervals, by sex and age Based on adjusted probability of separation in 1961, 1963, and 1964

\begin{tabular}{|c|c|c|c|c|c|c|c|c|c|c|c|c|c|}
\hline \multicolumn{2}{|c|}{ Age Group (yrs) } & \multicolumn{3}{|c|}{$0-34$} & \multicolumn{3}{|c|}{$35-64$} & \multicolumn{3}{|c|}{65 and Over } & \multicolumn{3}{|c|}{ Total } \\
\hline Sex & $\cdots$ & Male & Female & Total & Male & Female & Total & Male & Female & Total & Male & Female & Total \\
\hline Year & $\begin{array}{l}1964 \\
1974 \\
1984 \\
1994 \\
2004 \\
2014\end{array}$ & $\begin{array}{r}79 \\
9 \\
0 \\
0 \\
0 \\
0\end{array}$ & $\begin{array}{r}98 \\
7 \\
0 \\
0 \\
0 \\
0\end{array}$ & $\begin{array}{r}177 \\
16 \\
0 \\
0 \\
0 \\
0\end{array}$ & $\begin{array}{r}561 \\
186 \\
82 \\
22 \\
8 \\
0\end{array}$ & $\begin{array}{r}424 \\
127 \\
58 \\
21 \\
3 \\
0\end{array}$ & $\begin{array}{r}985 \\
313 \\
140 \\
43 \\
11 \\
0\end{array}$ & $\begin{array}{r}245 \\
120 \\
61 \\
39 \\
13 \\
1\end{array}$ & $\begin{array}{r}519 \\
126 \\
57 \\
21 \\
12 \\
4\end{array}$ & $\begin{array}{r}764 \\
246 \\
118 \\
60 \\
25 \\
5\end{array}$ & $\begin{array}{r}885 \\
315 \\
143 \\
61 \\
21 \\
1\end{array}$ & $\begin{array}{r}1,041 \\
260 \\
115 \\
42 \\
15 \\
4\end{array}$ & $\begin{array}{r}1,926 \\
575 \\
258 \\
103 \\
36 \\
5\end{array}$ \\
\hline
\end{tabular}


others in Scotland, would continue to obtain despite the larger initial number of females. Even among patients aged 65 years and over, where there were twice as many women as men in the original mental hospital population as a whole, 10 years later they would be about equally divided between the sexes and thereafter males would be in the majority until after the fourth decade. The effect of ageing of the long-stay population is also clearly shown. The number of patients aged 65 years and over would form a progressively higher proportion of the whole, but would become a majority only after about 25 years.

\section{Discussion}

The numbers of patients shown in Table II are the numbers who would be expected to remain in mental hospital after each specified interval if the probability of their leaving hospital by death or discharge continues unchanged. Evidence has been presented which shows that there has not been any appreciable change in the expectation of separation since about 1956. The Table thus indicates the numbers of patients by sex and age for whom facilities would be required after each interval. The confidence with which the method and the figures produced by it may be used for planning purposes requires detailed discussion.

\section{Reliability and Validity of the Method AND THE RESULTS}

In introducing a method a central question is whether it has any advantages over alternatives to it. Although the method proposed by Tooth and Brooke (1961) has been widely used, there seems to be sufficient doubt about its accuracy to warrant searching for alternatives. Standard life-table method is undoubtedly appropriate to the problem and its reliability is well established in many applications. The drawback is in obtaining the data required from most mental hospital reporting systems, which are often quite crude. The method suggested here makes use of information which is usually obtainable from even rudimentary reporting systems. No attempt was made in this study to estimate the relative precision of the present method and standard life-table method. A comparison of results from both methods would be a valuable exercise which should be undertaken.

The two general questions which require answering, before the results of applying projective models of this kind can be used rationally, are:

(1) What are the sources of error, their size and their effect on the results.

2) What meaning (should be attached to the results.
The statistical procedures themselves constitute a $\infty$ practical model of the behaviour of a standing mental 8 hospital population in defined circumstances. Any 3 error which is introduced originates from incom- ? pleteness or unreliability of the data to which the procedures are applied. The critical test of reliability $\stackrel{?}{?}$ is whether the results of the projection are borne out in practice to the extent that would be expected, that is, to the extent that the conditions under which the projection would be true do in fact obtain. With the $\stackrel{\varnothing}{\AA}$ data available it was possible to make a direct esti- ळ mate of the actual numbers remaining in hospital after 1 and 2 years which could be compared with the

TABLE III

NORTH-EAST SCOTTISH MENTAL HOSPITALS PERCENTAGE DIFFERENCE, BETWEEN ACTUAL AND PROJECTED ONE-YEAR OUTCOME OF MEAN AND END-OF-YEAR RESIDENTS IN 1963

Based on adjusted and unadjusted probability of separation in 1960 , 1961 , and 1963

\begin{tabular}{|c|c|c|c|c|c|}
\hline \multirow{2}{*}{ Age (yrs) } & \multirow{2}{*}{ Projection } & \multicolumn{2}{|c|}{ Males } & \multicolumn{2}{|c|}{ Females } \\
\hline & & Mean & $\begin{array}{l}\text { End of } \\
\text { Year }\end{array}$ & Mean & $\begin{array}{l}\text { End of } \\
\text { Year }\end{array}$ \\
\hline $0-34$ & $\begin{array}{l}\text { Unadjusted } \\
\text { Adjusted }\end{array}$ & $\begin{array}{r}+4 \cdot 5 \\
+30.2\end{array}$ & $\begin{array}{r}+2 \cdot 1 \\
+28 \cdot 7\end{array}$ & $\begin{array}{r}-9 \cdot 2 \\
+7 \cdot 1\end{array}$ & $\begin{array}{r}-20.9 \\
-1.8\end{array}$ \\
\hline $35-64$ & $\begin{array}{l}\text { Unadjusted } \\
\text { Adjusted }\end{array}$ & $\begin{array}{l}-4 \cdot 3 \\
-1 \cdot 3\end{array}$ & $\begin{array}{l}-4.9 \\
-1.4\end{array}$ & $\begin{array}{r}-1 \cdot 3 \\
+5 \cdot 4\end{array}$ & $\begin{array}{l}-2 \cdot 2 \zeta \\
+4.3 z\end{array}$ \\
\hline $\begin{array}{l}65 \text { and } \\
\text { Over }\end{array}$ & $\begin{array}{l}\text { Unadjusted } \\
\text { Adjusted }\end{array}$ & $\begin{array}{r}-12 \cdot 2 \\
-6 \cdot 8\end{array}$ & $\begin{array}{l}-24.6 \\
-16.4\end{array}$ & $\begin{array}{l}-9 \cdot 1 \\
-3 \cdot 3\end{array}$ & $\begin{array}{l}-9 \cdot 1 \\
-3 \cdot 2 \bar{c}\end{array}$ \\
\hline
\end{tabular}

TABLE IV

NORTH-EAST SCOTTISH MENTAL HOSPITALS ACTUAL AND PROJECTED ONE- AND TWO-YEAR OUTCOMES OF 1963 END-OF-YEAR RESIDENTS Based on adjusted probability of separation in 1960, 1961, and 1963

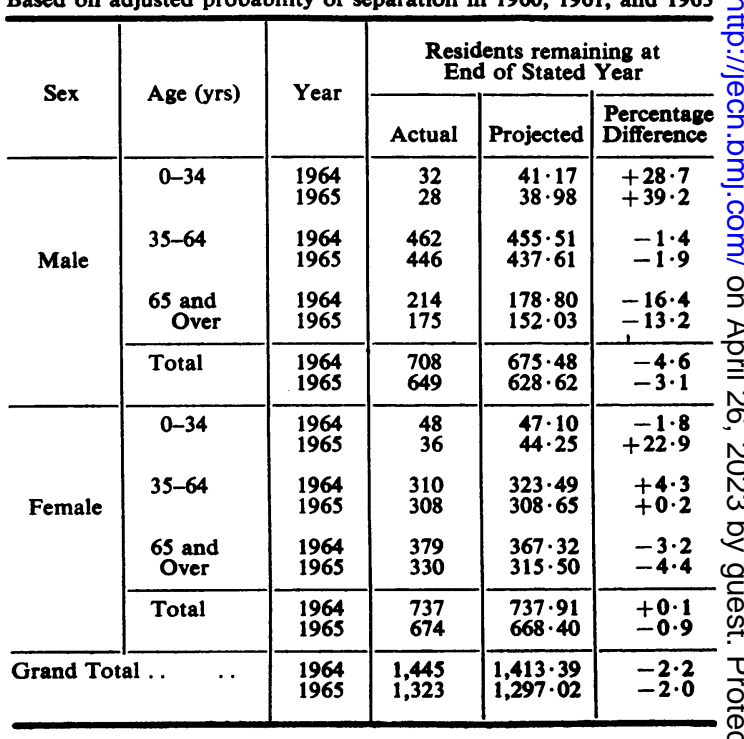


projected numbers. As each year passes, the comparison can be extended. The results are shown in Tables III and IV (opposite) and in Fig. 10.

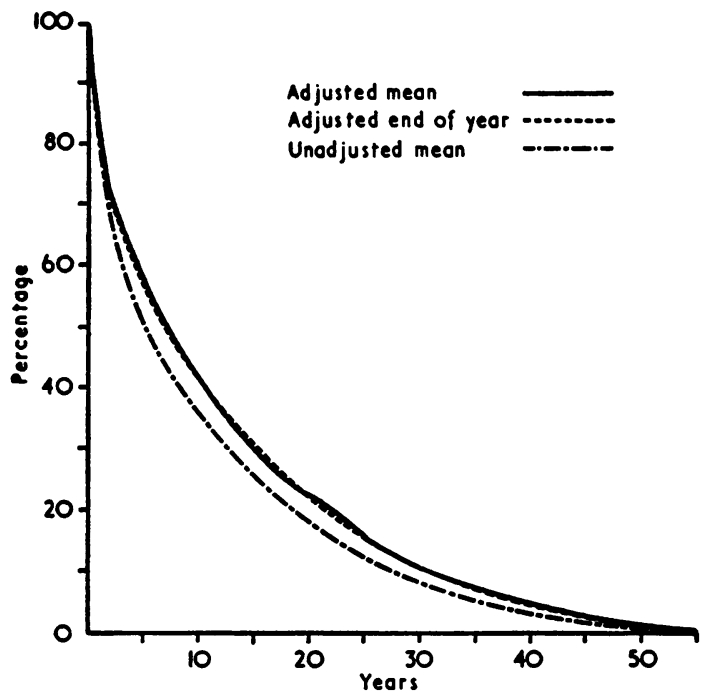

Fig. 10.-Projected outcome of resident population in 1963, based on probability of separation in 1960,1961, and 1963. Comparison of adjusted and unadjusted separations and mean and end-of-year populations.

Fig. 10 shows that projections of data on total mean and end-of-year residents did not differ in any important respect. The discrepancies of the adjusted and unadjusted projections of mean and end-of-year data from actual outcome after one year are shown for each age and sex group in Table III. Means gave more accurate results in half the groups and there were large differences in either direction in only a few cases. In general it was concluded that the use of mean rather than end-of-year resident figures made little difference to the accuracy of the projection. If means were not obtainable from available data, end-of-year figures would be adequate.

The adjustment of separation data for changes in the number of admissions in each year is more important. The unadjusted projection gave a more rapid attrition of the resident population than the adjusted projections (Fig. 10), and in all but two age/sex groups the adjusted projections were more accurate (Table III). Nevertheless it will be noted that, in males aged 0-34 years particularly, accuracy was reduced by making the adjustment.

Table IV shows the position after 1 and 2 years. The overall accuracy is good, the estimate being 2 per cent. too low and the figures for females being considerably better than those for males. It seems likely that the absence of age-specific information on admissions imposed the admission pattern of the 35 to 64-year age group, which had the largest numbers, onto the two smaller groups, thus accentuating the error in the projections for young and aged patients. The small numbers in the 0 to 34-year age group would also be expected to produce large fluctuations in the estimates.

Projections of this kind are in no sense statements of what will happen. They are statements of what can be expected to happen if the conditions existing under which they were calculated continue to obtain throughout the period over which the projection applies. For instance, if the number of available beds were increased or decreased, the numbers of admissions changed markedly, or discharge policy, the death rate, or treatment methods were to be altered, outcome would be affected and the probability of separation would change. Three important consequences follow from these constraints:

(a) Projections should be carried out for each region, hospital group, or even single hospitals, provided numbers are large enough, to take account of inter-regional and inter-unit variation.

(b) Projections should be recomputed regularly, or at least whenever evidence of change in separation rates appears.

(c) Projections should be carried out for a variety of hypothetical conditions to determine their effect. For example, the effect of doubling the separation rate for middle-aged males could be explored with a view to rehabilitation of able-bodied males to the community; the effect of shortening duration of stay of elderly females consequent on provision of more extensive local authority facilities could be specified; the required separation rate could be obtained in order to reach a defined goal, such as reduction of a particular age/sex group to a certain number.

Thus the method could be used as a tool for management and for conscious control of the mental hospital population.

\section{SUMMARY}

A review of surveys of mental hospital populations for planning purposes showed discrepancies in conclusions and in interpretation of results. Methods of estimating the attrition of a standing mental hospital population are examined and a method using direct estimates of probability of separation from hospital detailed. Results of application to North-East Scottish mental hospitals showed a curvilinear outcome with a relatively short period required to halve the population but a very long one to eliminate 
it. Marked differences were found between various age and sex groups. Little change was observed in projected outcome in the period 1956-64. The projected age and sex composition was obtained for the 1964 population of North-East Scottish mental hospitals at intervals of 10 years. The reliability and validity of the method and the results are discussed and some applications mentioned.

\section{REFERENCES}

Baldwin, J. A. (1963). Scot. med. J., 8, 227.

- Innes, G., Millar, W. M., Sharp, G. A., and Dorricott, N. (1965). Brit. J. prev. soc. Med., 19, 38.

Cooper, A. B., and Early, D. F. (1961). Brit. med. J., 1,1600 .
Cross, K. W., and Yates, J. (1961). Lancet, 1, 989.

Early, D. F., and Magnus, R. V. (1966). Brit. J. Psychiat., 112, 595.

Gore, C. P., and Jones, K. (1961). Lancet, 2, 544.

Hassall, C., and Hellon, C. P. (1964). Brit. J. Psychiat., 110, 183.

-_, Spencer, A. M., and Cross, K. W. (1965). Ibid. $111,420$.

Lindsay, J. S. B. (1962). Lancet, 1, 1354.

National Health Service (1962). "A Hospital Plan for England and Wales." Cmnd. 1604. H.M.S.O., London.

Norton, A. (1961). Brit. med. J., 1, 528.

Rehin, G. F., and Martin, F. M. (1963). "Psychiatric Services in 1975", Planning, 29, No. 468, p. 1. P.E.P. (Political and Economic Planning), London.

Tooth, G. C., and Brooke, E. M. (1961). Lancet, 1, 710.

\section{APPENDIX}

The method can be represented symbolically as follows:

Let $H_{i}$ be the number of separations in a given year of duration of stay $i$ (where $i$ is the number of completed years).

${ }_{x} \mathbf{P}_{l}$ be the probability of separation after a continued stay of $(x-i)$ years of patients of hospital age $i$.

$A_{i}$ be the number of admissions in the year $N-i$ where $N$ is the year the separations in which are under consideration.

$$
\text { Then } \quad{ }_{x} \mathrm{P}_{i}=\frac{H_{x} / A_{x}}{\sum_{y=i}^{n}\left(H_{y} / A_{y}\right)}
$$

where $n=\max i$, such that $H_{i>n}=0$

$$
\text { (Note: } \sum_{x=i}^{n}{ }_{x} \mathrm{P}_{i}=\frac{\sum_{x=i}^{n}\left(H_{x} / A_{x}\right)}{\sum_{y=i}^{n}\left(H_{y} / A_{y}\right)}=1 \text { ) }
$$

Refining the process to allow for age as well as hospital age, the above is modified as follows:

$H_{i,(j)}$ is the number of separations in a given year of duration of stay $i$ and age $j$.
${ }_{x} P_{i,(j)}$ is the probability of separation after continued stay of $(x-i)$ years patients of age $j$.

$$
\text { Then } \quad{ }_{x} \mathrm{P}_{i,(j)}=\frac{H_{x,(j+x-i)} / A_{x}}{\sum_{y=0}^{n-i}\left(H_{i+y,(j+y)} / A_{i+y}\right)}
$$

In practice it is necessary to group the ages in order to obtain useable figures. In most of this study groupings of 0 to 34 years, 35 to 64 years, and 65 years and over were used. Thus to complete the symbolic picture:

$H_{i,(j, k)}$ is the number of separations in a given year of duration of stay $i$ and of age $j$ to $k$ (inclusive).

${ }_{x} \mathrm{P}_{i,(j, k)}$ is the probability of separation after a continued stay of $(x-i)$ years of patients of age $j$ to $k$ inclusive.

$$
\text { Then } \begin{aligned}
{ }_{x} \mathrm{P}_{i,(j, k)} & =\frac{H_{x,(j+x-i, k+x-i)} / A_{x}}{\sum_{y=0}^{n-i}\left(H_{i+y,(j+y, k+y)} / A_{i+y}\right)} \\
& =\frac{y=j+x-i}{\sum_{z=0}^{n-i} \sum_{w=0}^{k-j}\left(H_{i+z,(j+w+z)} / A_{i+z}\right)}
\end{aligned}
$$


The actual projection of outcome of any set of residents is obtained by multiplying the number of residents in any age/hospital age category by the probabilities for the category, thereby obtaining a distribution of these residents over the range of duration of stay from 0 to $n$. Then, having done this for all age/hospital age categories, the values are summed by the durations of continued stay, thus giving the total picture of the outcome of the residents.
In symbols:

$\mathrm{R}_{i,(j, k)}$ is the number of residents in a given year, of hospital age $i$, and age range $j$ to $k$ (inclusive).

${ }_{v} S \quad$ is the predicted number of residents separating after a continued stay of $v$ years.

${ }_{v} S=\sum_{i=0}^{n} \sum_{(j, k)} R_{i,(j, k)} \times{ }_{v+i} \mathrm{P}_{i,(j, k)}$ 